\title{
A metrology enabled thermal imager for thermal vacuum
}

\author{
by Wesley Bond*, Vivek Panicker*,Jamie McMillian*, Rob Simpson*, Michael Hayes*, \\ Graham Machin*, Gianluca Casarosa**, James Etchells** \\ *NPL, National Physical Laboratory, Hampton Rd, Teddington, UK, Email: wesley.bond@npl.co.uk \\ ${ }^{*}$ ESA, ESTEC Keplerlaan 1, 2201 AZ Noordwijk, The Netherlands
}

\begin{abstract}
The ground testing of satellites necessitates the validation of their thermal model whilst operational in vacuum. Thermocouples are widely used for this testing, but they are only able to provide a point temperature measurement so a large number are used. A low-cost, in vacuum thermal imaging system however could determine the temperature of a large area. Such an approach can be used to supplement contact temperature measurements, thereby reducing the number of thermocouples required. NPL has completed the de-risking of such a thermal imager that can operate in thermal vacuum from $-40^{\circ} \mathrm{C}$ to $60^{\circ} \mathrm{C}$ and has a low instrument uncertainty of $\pm 1^{\circ} \mathrm{C}(k=2)$.
\end{abstract}

\section{Introduction}

Satellites are subject to a wide range of tests before being cleared for launch. A key part of this testing regime is an evaluation of system thermal performance during operation in thermal vacuum. In addition, such testing is also performed on a wide range of space hardware during development. In order to be certified a satellite is exposed to the temperatures, solar illumination and high vacuum it will experience in orbit and the operational temperature of its systems under these conditions is assessed. In order to perform these temperature measurements thermocouple sensors are placed throughout the satellite to determine key component temperatures during the thermal balance testing. These results are used in tandem with the thermal model of the satellite to judge the effectiveness of its thermal control systems. Additional surface temperature data can also be gathered by using a thermal imager in tandem with thermocouple measurements, with these results being incorporated into the thermal qualification of the satellite or treated as a separate source of semi-quantitative data. The nature of thermal imaging means that an imager is able to produce data that is superior to thermocouples in a number of ways, such as response time, spatial resolution and the lack of a need to physically influence the surface. However, the ability of a thermal imager to determine true surface temperatures is hampered by the variable emissivity of the satellite surface and often strong simulated solar flux illuminating the satellite under test.

The aim of this research was to de-risk the use of a commercial off the shelf thermal imager with a low size, weight and power requirement for use in thermal vacuum. In addition to the adaption of the thermal imager to reduce outgassing and increase its maximum operating temperature in vacuum, a full calibration was also performed. This calibration used low uncertainty National Physical Laboratory (NPL) reference blackbodies [1] to ensure a level of traceability to the temperature measurement performed. Checks were also made to ensure that the measurement capability of the thermal imager was not negatively affected by the vacuum environment, and recommendations for future development were made. The eventual goal of this development is a fully capable vacuum thermal imager that can assist in satellite testing and other temperature measurement requirements in vacuum.

\section{State of the art \& thermal imager selection}

A small number of thermal imagers are currently used for temperature monitoring during satellite testing, these are mostly contained within a windowed canister to maintain atmospheric pressure as shown in Fig. 1 [2]. This was previously the best option due to the requirements of vacuum testing, but this adaption makes the imaging system more expensive, more inflexible and adds additional uncertainties. Because of this, other thermal imagers have previously been adapted to work in vacuum, including in orbit [3]. Vacuum ready imagers were initially only suitable for qualitative imaging and not suitable for quantitative temperature measurements but this has now changed, with the de-risking of the technology enabling canister free measurements to be performed by the European space agency (ESA) during thermal vacuum testing.

Such quantitative performance is required for numerous applications, and these applications were considered during this initial development phase. Examples include vacuum testing key space hardware components such as heat pipes and telecoms panels in addition to studying the impacts of the thermal vacuum environment on satellites, such as thermoelastic deformation. 


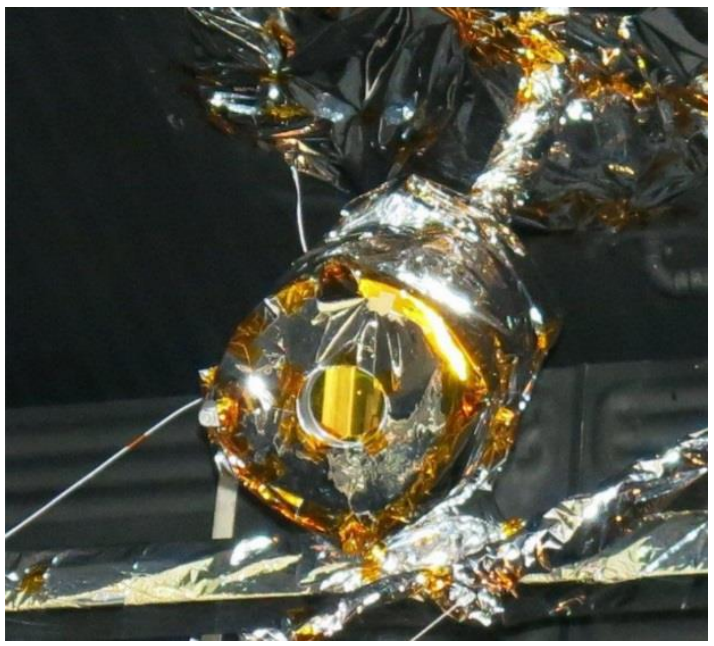

Fig. 1. Canister with viewport for thermal imager connected to atmosphere by flexible hose [2]

\subsection{Comparison to existing technologies}

The table below (Table 1) provides a technical and practical comparison between contact temperature sensors, a thermal imager within a canister and a vacuum ready thermal imager. This comparison highlights the fundamental advantages of the technology as well as the aspects where further development is requirements.

Table 1. Comparison to existing technologies

\begin{tabular}{|c|c|c|c|}
\hline $\begin{array}{l}\text { Aspect of } \\
\text { usage }\end{array}$ & $\begin{array}{l}\text { Contact temperature } \\
\text { sensor }\end{array}$ & $\begin{array}{l}\text { Thermal Imager within } \\
\text { canister }\end{array}$ & Vacuum ready thermal imager \\
\hline $\begin{array}{l}\text { Temperature } \\
\text { measurement } \\
\text { uncertainty }\end{array}$ & $\begin{array}{l}\text { Thermocouple }< \pm 0.5 \mathrm{~K} \\
\mathrm{PRT}< \pm 0.1 \mathrm{~K}\end{array}$ & $\begin{array}{l}< \pm 0.8^{\circ} \mathrm{C}(\text { Calibration } \\
\text { uncertainty) }\end{array}$ & $< \pm 1.1^{\circ} \mathrm{C}$ (Calibration uncertainty) \\
\hline $\begin{array}{l}\text { Temperature } \\
\text { measurement } \\
\text { range }\end{array}$ & $-250^{\circ} \mathrm{C}$ to $2000^{\circ} \mathrm{C}$ & $\begin{array}{l}-20^{\circ} \mathrm{C} \text { to } 1000^{\circ} \mathrm{C} \\
\text { (Qualitative assessment } \\
\text { below }-20^{\circ} \mathrm{C} \text { ) }\end{array}$ & $\begin{array}{l}-15^{\circ} \mathrm{C} \text { to } 140{ }^{\circ} \mathrm{C} \text { (Current } \\
\text { calibration) } \\
-40^{\circ} \mathrm{C} \text { to }>500^{\circ} \mathrm{C} \text { (Full Calibration) }\end{array}$ \\
\hline $\begin{array}{l}\text { Typical } \\
\text { Spatial } \\
\text { resolution }\end{array}$ & $\begin{array}{l}>10 \mathrm{~mm} \\
\text { (Physically limited by } \\
\text { installation) }\end{array}$ & $\begin{array}{l}>3 \mathrm{~mm} \\
\left(\text { Assuming } 40^{\circ} \text { field of view }\right. \\
\text { at } 3 \mathrm{~m} \text { ) }\end{array}$ & $\begin{array}{l}>3 \mathrm{~mm} \\
\text { (Assuming } 40^{\circ} \text { field of view at } 3 \mathrm{~m} \text { ) }\end{array}$ \\
\hline $\begin{array}{l}\text { Measurable } \\
\text { area }\end{array}$ & $\begin{array}{l}\text { Areas where surface is } \\
\text { suitable for temperature } \\
\text { sensor placement. }\end{array}$ & $\begin{array}{l}\text { Exterior surfaces in thermal } \\
\text { imager direct line of sight \& } \\
\text { field of view. }\end{array}$ & $\begin{array}{l}\text { All exterior surfaces and larger } \\
\text { internal voids where possible. }\end{array}$ \\
\hline Response time & $1 \mathrm{~s}$ to $60 \mathrm{~s}$ & $0.01 \mathrm{~s}$ to $1 \mathrm{~s}$ & $0.02 \mathrm{~s}$ to $1 \mathrm{~s}$ \\
\hline $\begin{array}{l}\text { Installation } \\
\text { effort }\end{array}$ & $\begin{array}{l}\text { Time consuming and } \\
\text { complicated process. }\end{array}$ & $\begin{array}{l}\text { No work on target needed, } \\
\text { canister installation \& } \\
\text { maintenance required. }\end{array}$ & $\begin{array}{l}\text { Lower installation and maintenance } \\
\text { effort than canister imagers }\end{array}$ \\
\hline Installation cost & $\begin{array}{l}\text { High installation cost. } \\
\text { Large number of probes } \\
\text { and connections required, } \\
\text { data acquisition and } \\
\text { handling required. Major } \\
\text { elements are reusable. }\end{array}$ & $\begin{array}{l}\text { Moderate installation cost. } \\
\text { Protective canister needed \& } \\
\text { requires additional support } \\
\text { apparatus. System is } \\
\text { reusable. }\end{array}$ & $\begin{array}{l}\text { Low installation cost. } \\
\text { Thermal imager is low size, weight, } \\
\text { power and cost. Has fewer } \\
\text { requirements as a vacuum ready } \\
\text { system. } \\
\text { System is reusable. }\end{array}$ \\
\hline
\end{tabular}




\subsection{Thermal imager requirements and selection}

The specifications of a wide range of thermal imagers and imager cores were evaluated against a set of key requirements which were:

- High resolution: This will enable small surface features to be resolved, minimum array size of $640 \times 480$ pixels.

- Field of view flexibility: If the imager core supports a wide range of lenses it can be used optimally at more distances.

- Temperature survivability: A higher 'off the shelf' maximum operating and storage temperature will be advantageous when adapting the thermal imager core to operate in the wide temperature range experienced in thermal vacuum.

- $\quad$ Low size weight and power (SWAP): The less demanding the specifications of the thermal imager core the more easily it can be used in different measurement scenarios and adapted for thermal vacuum.

- Low cost: This would will lower the barrier for entry, in addition to making it more practical to use multiple imagers.

Based upon these requirements the thermal imager core selected was the FLIR Boson. It was the newest off the shelf product available and offered some of the best specifications in key areas. This includes a high resolution $(640 \mathrm{x}$ $512)$, a wide range of lens options available ( $4^{\circ}$ to $95^{\circ}$ horizontal field of view) and a non-operating temperature survival range of $-50{ }^{\circ} \mathrm{C}$ to $105^{\circ} \mathrm{C}$. The Boson is also a low SWAP device, with dimensions of approximately $30 \times 30 \times 40 \mathrm{~mm}$ in size, a weight of 44 grams and power consumption - as tested in vacuum - of $\sim 950 \mathrm{~mW}$ to $1400 \mathrm{~mW}$.

\section{Initial testing and calibration}

The FLIR Boson thermal imager core was calibrated under laboratory conditions as a baseline test and to inform the method for the calibration in thermal vacuum. The raw digital level from each pixel in the region of interest, shown as a white circle in Fig. 2, was measured when viewing a series of blackbody targets of known temperature. An equation to convert from the raw digital level to a temperature value for each pixel could then be generated. This calibration across a blackbody target range of $-40^{\circ} \mathrm{C}$ to $140^{\circ} \mathrm{C}$ resulted in an initial off the shelf temperature measurement uncertainty of \pm 6.2 ${ }^{\circ} \mathrm{C}(k=2)$. Based upon this calibration numerous improvements to the calibration procedure were identified. The coverage factor $(k=2)$ provides a coverage probability of approximately $95 \%$. The uncertainties stated throughout this paper were calculated in accordance with the "Guide to the expression of uncertainty in measurement" (GUM) [4].

The sources of uncertainty for thermal imager measurement were also evaluated as part of the calibration. The size of source results [5] showed that a target size of $30 \mathrm{~mm}$ or larger at a $700 \mathrm{~mm}$ observation distance was needed to reliably measure the temperature at the target centre (meaning the difference between the temperature the imager determined and the temperature of the blackbody was $\left.<0.8^{\circ} \mathrm{C}\right)$. The stability of the thermal imager was $\pm 0.21^{\circ} \mathrm{C}(k=1)$ when viewing a blackbody stable to $<0.1{ }^{\circ} \mathrm{C}$ drift $/ \mathrm{hr}$, as determined through the standard deviation of measurements during this period. The non-uniformity across the frame was also measured and found to be $\pm 0.62{ }^{\circ} \mathrm{C}(k=2)$ when viewing a flat plate blackbody at $50^{\circ} \mathrm{C}$, as determined through the standard deviation of pixel values across the image. The area of the flat plate blackbody used for calibration had a non-uniformity of $\pm 0.2^{\circ} \mathrm{C}$ at $50^{\circ} \mathrm{C}$ [6]. The size of source effect and stability were also measured in vacuum and the improvement achieved is detailed in section 5 .

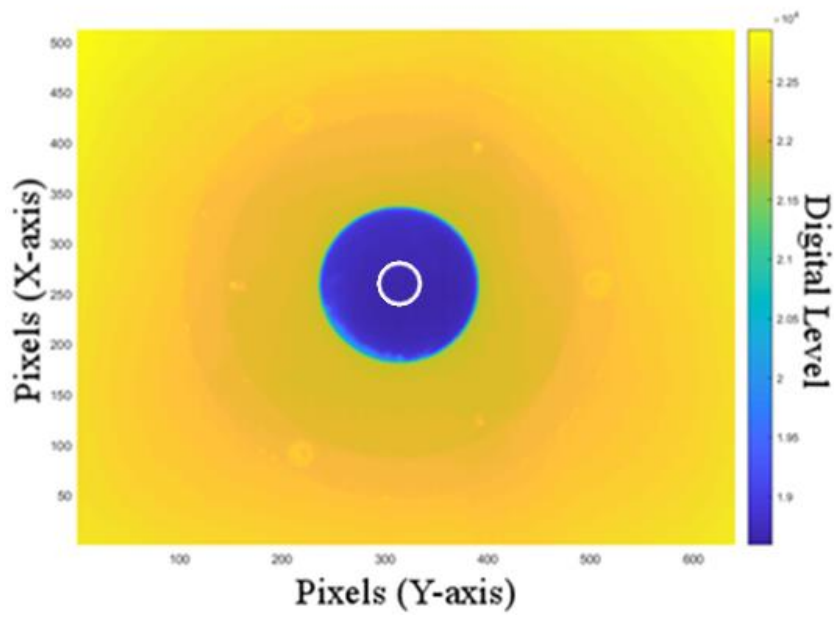

Fig. 2. Thermal image of $-40{ }^{\circ} \mathrm{C}$ blackbody target as observed at $300 \mathrm{~mm}$ calibration distance, the region of interest from which the pixels were used to measure the blackbody temperature is shown as a white circle. 


\section{Vacuum adaption and operation}

For vacuum testing, a thermal vacuum facility was established at NPL. This was developed to reach a vacuum of less than $1 \times 10^{-4}$ mbar and temperatures in the range of $-40^{\circ} \mathrm{C}$ to $125^{\circ} \mathrm{C}$. Key components for the project such as an infra-red transparent window, temperature sensors and the USB feedthrough currently used to connect to the thermal imager were also installed. These were then tested and calibrated as required.

There are a number of things that need to be considered when adapting a thermal imager core for vacuum before developing the temperature measurement capability of the device, with the first being that the electronics survive under vacuum conditions for extended durations. The lack of atmosphere was also expected to result in a higher operating temperature and the potential for outgassing. The thermal aspects of the thermal imager operation were assessed before vacuum exposure using COMSOL modelling and operating the thermal imager at atmospheric pressure within the temperature-controlled vacuum chamber. This modelling and data showed that the thermal imager could operate in vacuum at ambient temperature without overheating, so modifications were minimal for the initial exposure.

Before exposure to vacuum, the materials within the thermal imager were analysed and components that could significantly outgas were removed and replaced. The modified thermal imager was then degassed at nominally $90{ }^{\circ} \mathrm{C}$ and a vacuum of nominally $5 \times 10^{-4}$ mbar over a time period of 72 hours. The total mass loss was measured at $0.04 \%$ compared to the $1 \%$ limit of the ESA standard and the Collected Volatile Condensable Material (CVCM) mass increase was $0.003 \%$ compared to the $0.1 \%$ of the standard [7]. The maximum degassing temperature was limited by the thermal imager nonoperational temperature limit, however despite this limitation the results from the outgassing are positive and future testing to a higher specification should yield outgassing performance within acceptable limits.

To ensure successful thermal management of the imager multiple changes were required. Without these the initial maximum vacuum operating temperature of the thermal imager was $48.5^{\circ} \mathrm{C}$. Conductive pathway and radiative improvements to the heat dissipation of the thermal imager increased the maximum viable operating temperature by nominally $4^{\circ} \mathrm{C}$, but the largest change came from simplifying the imaging pipeline. This change reduced the utilisation of the main processor within the thermal imager, with this processor being the limiting factor as it was the hottest component when operating. The result was a further increase in the operating vacuum temperature limit of nominally $8^{\circ} \mathrm{C}$. This resulted in a final maximum vacuum operating temperature of $60.3^{\circ} \mathrm{C}$, and this capability was confirmed over extended periods.

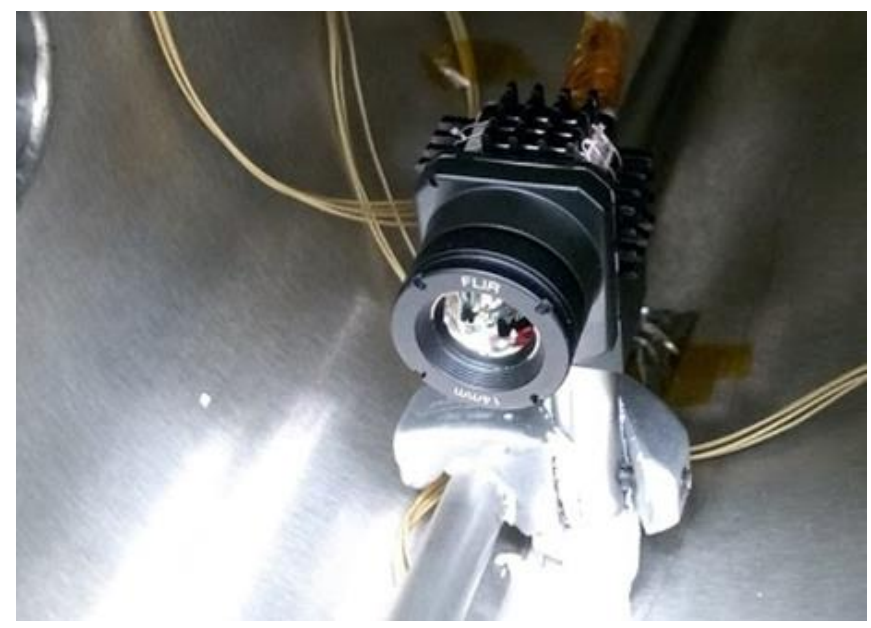

Fig. 3. Modified Boson thermal imager in place within vacuum chamber

\subsection{Vacuum temperature impact on thermal imager}

For the initial vacuum testing, the thermal imager core was placed in the vacuum chamber (Fig. 3) and operated whilst experiencing a range of vacuum temperatures from $-37^{\circ} \mathrm{C}$ to $49^{\circ} \mathrm{C}$. External NPL high emissivity cavity blackbodies were used as temperature references [1] and these were viewed through a zinc-selenide infra-red transparent window.

During initial testing the external cavity blackbody was observed at five temperatures between $-14.8^{\circ} \mathrm{C}$ and $80.0^{\circ} \mathrm{C}$, and these measurements were performed whilst operating at several vacuum temperatures. This thermal imager setup is shown in full in Fig. $\mathbf{5 .}$ 
The initial measurements showed the digital value generated by the thermal imager array was highly dependent on the focal plane array (FPA) temperature, but that the impact of the dependence was repeatable. This can be seen in Fig. 4 where the digital level measured for a blackbody at the same temperature varies according to the FPA temperature. A correction could be applied to account for this temperature dependant response and it is clear that maintaining the thermal imager operating temperature as stable as reasonably practical would be advantageous.

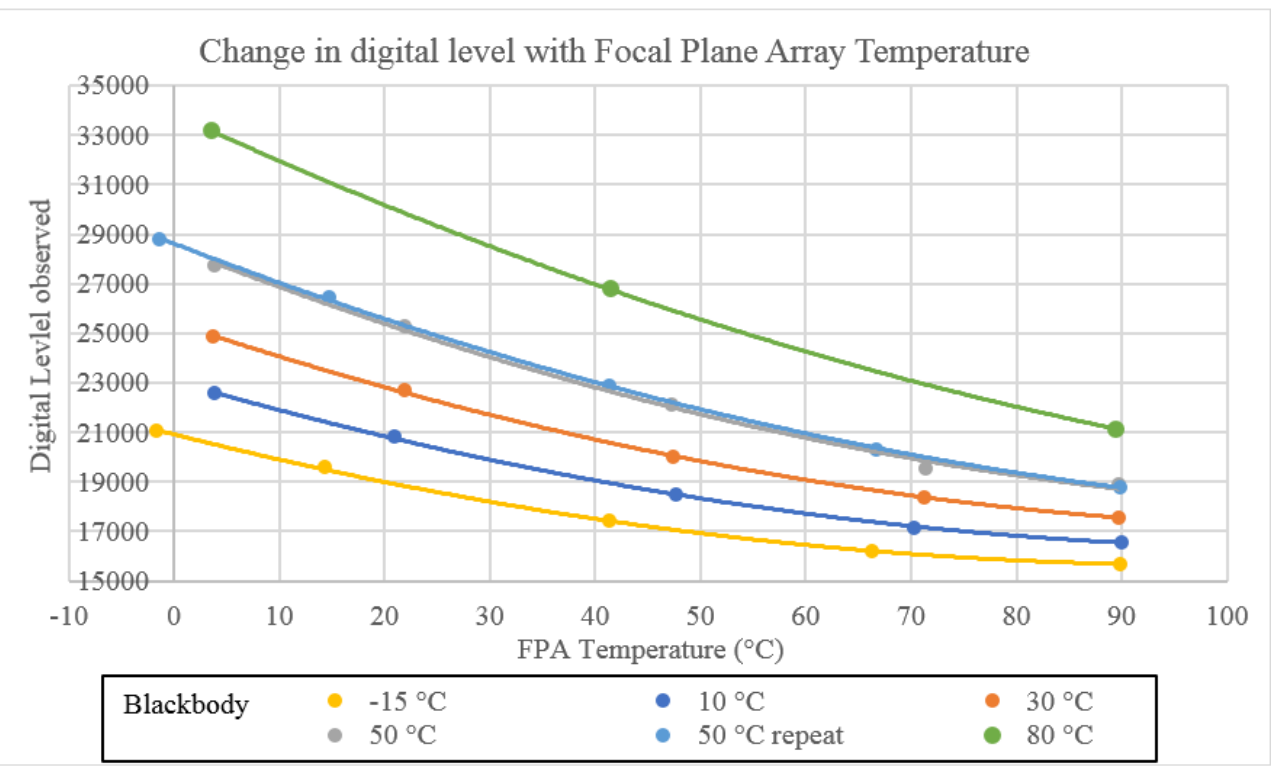

Fig. 4. Graph showing impact on the digital value measured at different operating temperatures

\section{Vacuum calibration}

The main calibration of the Boson thermal imager core was carried out under vacuum conditions at test chamber temperatures of $-35^{\circ} \mathrm{C}, 10^{\circ} \mathrm{C}$ and $54^{\circ} \mathrm{C}$. The calibration blackbody temperature was varied between $-15^{\circ} \mathrm{C}$ to $140{ }^{\circ} \mathrm{C}$, with seven temperatures used.

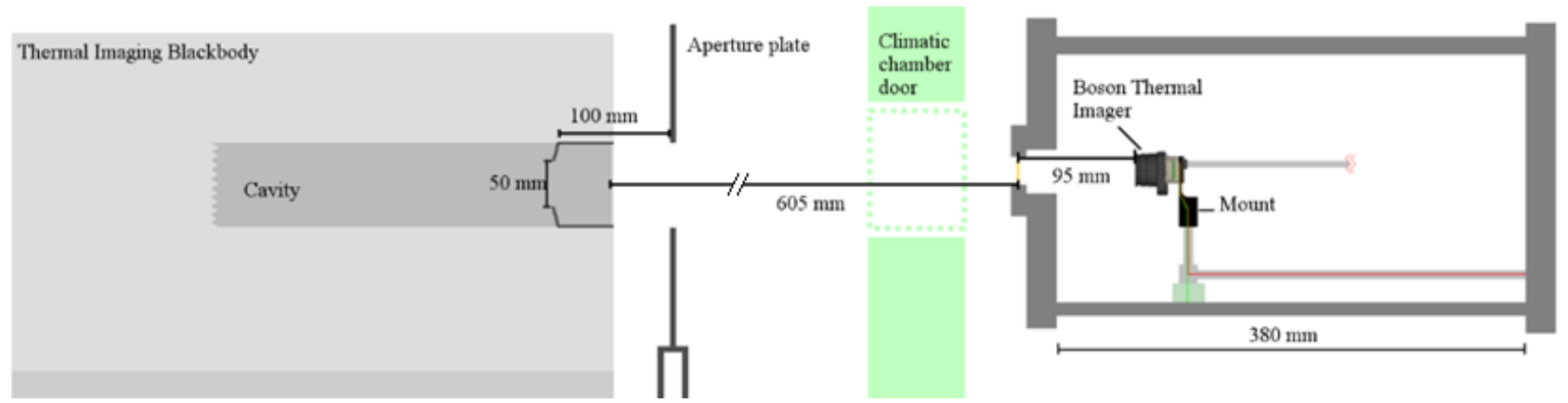

Fig. 5. Diagram showing calibration setup for thermal imager when mounted within vacuum chamber which was within the climatic chamber.

The cavity blackbody measurements resulted in three calibrations for three vacuum temperatures. These in vacuum calibrations had uncertainties between $\pm 0.75^{\circ} \mathrm{C}$ and $\pm 1.05^{\circ} \mathrm{C}(k=2.5)$ and the calibration fit from raw digital level to temperature is shown below in Fig. 6 . This positive result within vacuum shows the future potential of such a thermal imager for quantitative measurement if calibrated correctly, in addition the measurement uncertainties were greatly improved compared to the 'off the shelf' performance as described in section 3 . The total application uncertainty at this development stage is still notably higher than the calibration uncertainty, with the main factors accounting for this being non-uniformity across the thermal image and the change in response at different operating temperatures. These will impact measurements in addition to application specific contributions to uncertainty such as uncertain surface emissivity and reflected thermal radiation. 


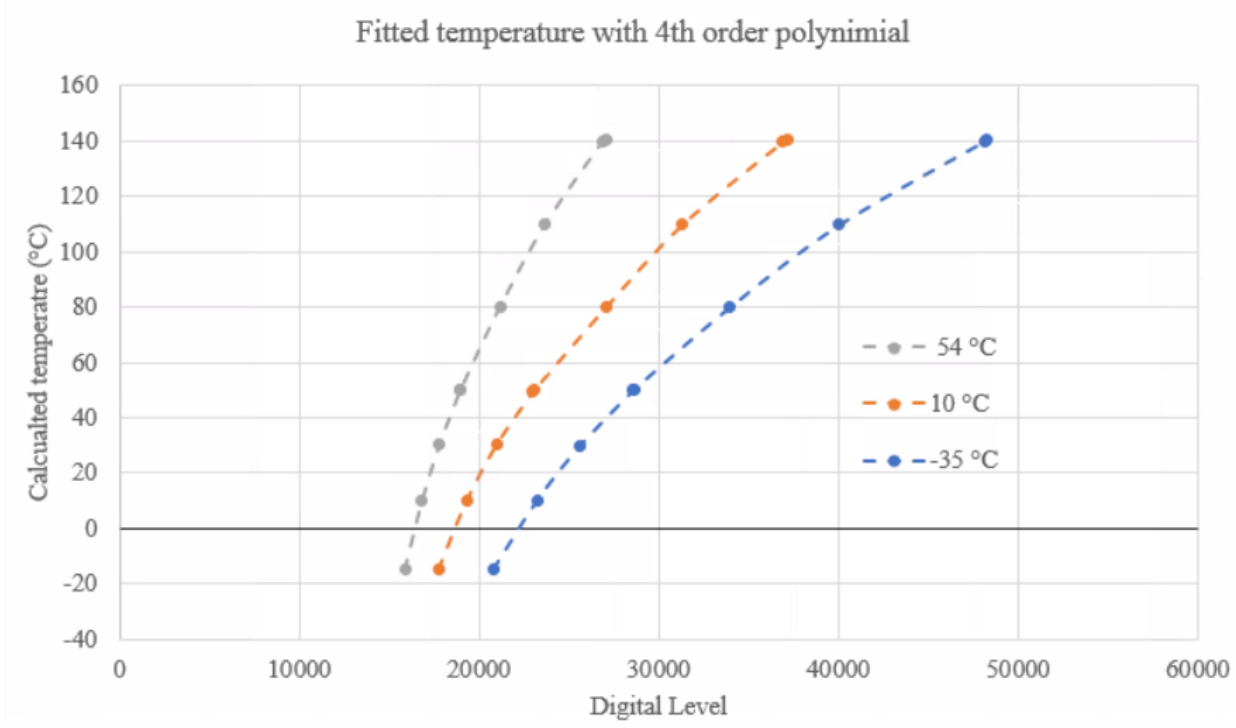

Fig. 6. Calibration of thermal imager showing conversion from raw digital level to calculated temperature at each operating vacuum temperature

The size of source effect analysis under vacuum conditions showed that a target of $15 \mathrm{~mm}$ or larger at a $700 \mathrm{~mm}$ observation distance is required to measure a reliable temperature at the target's centre. The temperature measurement stability of the thermal imager was $\pm 0.13^{\circ} \mathrm{C}(k=1)$. It is worth noting that both of these results show an improvement compared to the initial laboratory assessment due to the hardware and software modifications carried out.

An initial analysis of the post-processing filters employed in the Boson imaging pipeline was also carried out. This showed that the majority of the filters employed to improve the appearance of the image were detrimental to quantitative measurement performance, however others show potential in correcting issues such as non-uniformity across the image. A central area of $560 \times 420$ pixels (from the $640 \times 512$ array) was identified as a realistic area for future quantitative thermal imaging, as opposed to a calibration of the full frame.

\section{Vacuum blackbody and internal calibration}

A simple vacuum blackbody cavity was constructed to facilitate an in vacuum validation. This was built from vacuum compliant materials and had a temperature uncertainty of $\pm 0.48{ }^{\circ} \mathrm{C}(k=2)$ when operating at $40{ }^{\circ} \mathrm{C}$ under ambient conditions. A photograph of the blackbody is shown in Fig. 7. The small size of the vacuum chamber limited the size of the blackbody cavity to a $40 \mathrm{~mm}$ diameter and $70 \mathrm{~mm}$ depth. The internal surfaces were coated with high emissivity Aeroglaze z306 paint. This geometry was analysed using the STEEP 3 software package [8] and was calculated to have an emissivity of greater than 0.996 .

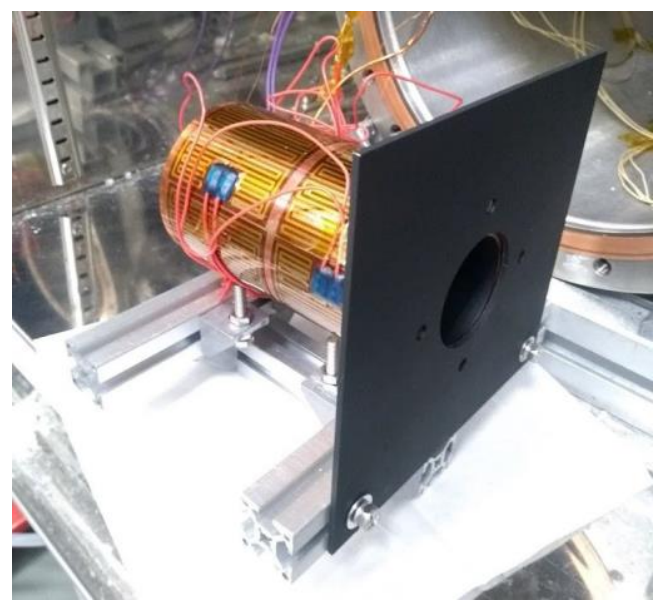

Fig. 7. Aperture view of the blackbody in front of vacuum chamber, vacuum compatible high emissivity coating on aperture plate and cavity are visible. 
The in-vacuum validation took place with target temperatures in the range of $-30^{\circ} \mathrm{C}$ to $140{ }^{\circ} \mathrm{C}$ across three vacuum chamber temperatures of $-33^{\circ} \mathrm{C}, 11^{\circ} \mathrm{C}$ and $52{ }^{\circ} \mathrm{C}$. The calibration uncertainty for the vacuum calibration was calculated to be between $\pm 2.7^{\circ} \mathrm{C}(k=2.6)$ and $\pm 5.6^{\circ} \mathrm{C}(k=2.9)$, with the highest uncertainty occurring at the highest operational temperature. This higher uncertainty in measurement was due to the higher blackbody uncertainty and the temperature changes the blackbody itself caused within the vacuum chamber.

The stability of the thermal imager was also measured using the in vacuum blackbody and was found to be $\pm 0.13^{\circ} \mathrm{C}$, the same result as that measured using the external blackbody.

\section{Temperature measurement drift check}

During the course of this research project nine drift checks were carried out on the thermal imager core over a six-month period. Each check took the form of a simplified four temperature point calibration using a flat plate blackbody under stable ambient conditions, with calibration temperatures of $50^{\circ} \mathrm{C}, 80^{\circ} \mathrm{C}, 110{ }^{\circ} \mathrm{C}$ and $140^{\circ} \mathrm{C}$ used. The first drift check took place in tandem with the initial calibration and the final drift check was performed after the final vacuum operation had taken place. The area of the flat plate blackbody used for calibration had a accuracy of $\pm 0.35^{\circ} \mathrm{C}$ at $35^{\circ} \mathrm{C}$ and $\pm 0.7^{\circ} \mathrm{C}$ at $200^{\circ} \mathrm{C}$.[6]

A drift check was required after a modification to the imager had taken place or if the device was vacuum cycled. Over the course of these modifications and over 1800 hours of vacuum exposure no drift check showed a change from the mean result of more than 200 digital levels, as shown in Fig. 8. This was the case at all four calibration temperatures. In terms of calibrated temperature this represents long-term stability of better than $\pm 0.85^{\circ} \mathrm{C}$.

Based upon these drift check results no long-term drift in the temperature measured by the thermal imager was identified due to vacuum exposure or modification. This is an important finding when considering long term use in thermal vacuum facilities.

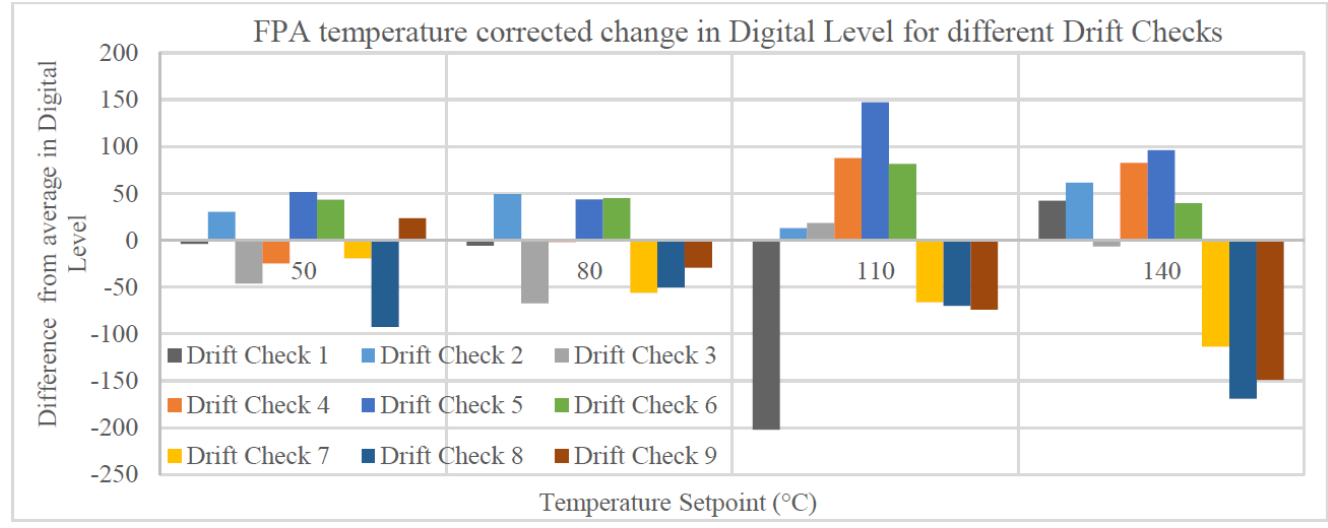

Fig. 8. Stability of thermal imager over six-month period showing minimal change in digital level

\section{Future development and applications}

The aim of this research was to 'de-risk' the use of a low SWAP thermal imager in thermal vacuum and to lower its measurement uncertainty. Now that this goal has been accomplished the next stage will be the development of a prototype thermal imager based upon our findings; this second-generation device will be used to gather data during space hardware thermal vacuum testing and to further improve measurement performance to develop the final vacuum-ready thermal imager. The electronic and data interfaces required for final applications will also need to be developed at this stage. Research is also currently ongoing to address the challenge of thermal imager temperature measurement for materials of lower emissivity in complex environments, such as thermal vacuum test. This will allow for the correction of the observed surface temperature to the actual surface temperature with increased accuracy under all conditions.

A vacuum ready thermal imager with fully developed hardware and software could have numerous uses such as the close examination of internal systems that cannot be imaged by the current larger canister thermal imagers available. In addition, the non-contact nature of the measurement is ideally suited for components too light or sensitive for the use of a contact sensor. Looking further ahead a flight qualified thermal imager could perform the same vital monitoring tasks in orbit, with further stages of development being required to prepare the thermal vacuum imager for use in this environment. 


\section{Conclusion}

A thermal imager core was selected against defined criteria and was then assessed and successfully adapted for use in thermal vacuum. The adapted device subsequently showed the ability to operate across a range of vacuum temperatures without long term drift. In addition, three vacuum calibrations were carried out with uncertainties of $\pm 1.05^{\circ} \mathrm{C}$ $(k=2.5)$ or less. Other aspects such as the temperature measurement correction under different vacuum conditions also show clear routes to improvement. This de-risking represents a robust starting point for future improvements to the system's measurement capabilities. We have shown that low uncertainty, traceable measurement is feasible using a vacuum capable thermal imager.

Looking ahead this modified thermal imager has shown excellent potential for numerous thermal vacuum applications and no major issues were found when using an uncooled thermal imager in a thermal vacuum environment. Potential operational issues already identified as requiring study - such as outgassing and higher operating temperature - were successfully addressed. These factors combined make the development of a vacuum ready thermal imager a clear goal for continued research.

\section{Acknowledgments}

This research was funded by the ESA General Support Technology Programme (GSTP) and NPL wishes to thank ESA and the UK Space agency for their support. 


\section{REFERENCES}

[1] Machin, G., Simpson, R.C. \& Broussely, M., “Calibration and validation of thermal imagers”, QIRTJ, 6, p. 133-147 (2009) http://doi.org/10.3166/qirt.6.133-147

[2] Daniel Döring, Christian Spiessberger, Peter Jens Hein, "Temperature measurement in thermal-vacuum tests for spacecraft qualification - possibilities for infrared thermography", Quantitative InfraRed Thermography 2016

[3] Dee W. Pack, David R. Ardilla, 2017, "Two Aerospace Corporation CubeSat Remote Sensing Imagers: CUMULOS and R3"

[4] JCGM 100: 2008, "Evaluation of measurement data - guide to the expression of uncertainty in measurement," Bureau International des Poids et Mesures, Paris, 2008

[5] Machin, G., \& Ibrahim, M., "Size of Source Effect and temperature uncertainty II: low temperature systems", In: Tempmeko99, The 7th International Symposium on Temperature and Thermal Measurements in Industry and Science, Delft, The Netherlands, Eds. J. Dubbeldam \& M. J. de Groot, Published: IMEKO/NMi-VSL, p. 687-692 (1999)

[6] 4180, 4181 Precision Infrared Calibrator Technical Guide (c) Fluke Corporation 2013

[7] ECSS-Q-ST-70-02C "Space product assurance: Thermal vacuum outgassing test for screening of space materials", 2008

[8] STEEP 3 Version 1.3 @ Virial Inc. 